\title{
ORIGINS OF HETEROSPORY AND THE SEED HABIT: THE ROLE OF HETEROCHRONY
}

\author{
William A. DiMichele ${ }^{1}$, Jerrold 1. Davis ${ }^{2}$ and Richard G. Olmstead ${ }^{3}$
}

\begin{abstract}
Summary
The origin of the seed-plant life history, and subsequent diversification of seed morphology, should be considered two independent, fundamentally distinct evolutionary problems. Gametophytic endospory may have arisen paedomorphically from homosporous ancestors, specifically by progenesis in the gametophyte generation. Heterospory and gametophytic unisexuality are not necessarily evolutionary antecedents of endospory; rather, they may have arisen as developmental consequences of endospory. Once seeds existed, their early pattern of diversification was not one of gradual change in form, but of a proliferation of integumentary types differing widely from one another. Subsequently, the morphological spectrum narrowed, with closed integuments eventually prevailing. This two-stage pattern of diversity suggests an initial phenotypic breakthrough into a largely "empty" adaptive zone, followed by intensified biotic competition as the adaptive zone filled.
\end{abstract}

\section{Introduction}

The seed habit is the most complex and diverse means of sexual reproduction in vascular land plants. Since their first appearance in the Late Devonian, seed plants have come to dominate almost every terrestrial ecosystem. They also encompass a greater range of habit than any other group of Tracheophytes. The ecological diversity of this group generally is attributed to their reproductive system, which permits these plants to exploit habitats not accessible to most lower vascular plants.

Evolution of the seed habit consists of at least two independent problems. First is the evolution of the life history we call the seed habit, i.e., the delivery of a male gametophyte to a female gametophyte that is fixed on the parent sporophyte. Second is the evolution of ovular, particularly integumentary, morphology. In this paper we suggest that heterosporous life cycles characterized by endosporic gametophytes, including free-sporing heterospory and the seed habit, may have arisen by heterochronic processes (sensu Gould, 1977), specifically in the gametophytic life history phase. We suggest further that heterospory is not a necessary antecedent of endospory. Indeed, heterospory may have evolved in some lineages as an epigenetic consequence of endospory, via changes in developmental patterns inherent to endosporic gametophytes.

Diversification of ovular structure begins during the Late Devonian with one or a few basic ovular forms (Gillespie et al., 1981). This relatively long interval of morphological conservatism is followed in the early Lower Carboniferous by the abrupt appearance of a diversity of ovular types, representing a broad spectrum of morphologies (Long, 1975). Subsequent to this diversification there occurs a narrowing of the integumentary spectrum to "modern" form. This diversity pattern suggests a sequence of events beginning with a phenotypic breakthrough into an ecological-selective landscape of low or no interspecific competition ("n-selection" of Arthur, 1984). As adaptive space filled, an increase in biotic

1 Department of Paleobiology, National Museum of Natural History, Smithsonian Institution, Washington, DC 20560, U.S.A.

2 L. H. Bailey Hortorium, Cornell University, Ithaca, NY 14853-4301, U.S.A.

3 Department of Biology, University of Michigan, Ann Arbor, MI 48109-1048, U.S.A. 
interactions, within and between populations, led to a narrowing of the spectrum of basic ovular architectures, while the total number of species within seed-plant lineages continued to increase (Niklas et al., 1983). This overall pattern does not appear to represent a single evolutionary lineage in which gradual, adaptively driven ensheathment of the megasporangium by integuments occurred. Because of imprecision in the stratigraphic record of these early seeds, it is possible that some ancestor-descendant pattern is preserved. Also possible is that this pattern reflects a polytopic or polyphyletic radiation.

Current theories on the morphological evolution of heterospory derive primarily from comparative morphology of living plants. The structure of Devonian gametophytes is conjectural in almost all instances. The fossil record does exhibit a pattern of gradual increase in the maximum diameter of spores during the Devonian, reaching $210 \mu \mathrm{m}$ by the Middle Devonian (Emsian). This is the minimum size characteristic of modern spores bearing endosporic females (Chaloner, 1967; Andrews et al., 1974). However, it is not until the Late Devonian (Frasnian) that a distinct bimodality first develops between "microspore"-sized and "megaspore"-sized spores, which suggests that true heterospory (as opposed to anisospory) did not evolve until this time (Chaloner, 1967; Bell, 1979). Ovules, as recognized by integuments enclosing megasporangia and megaspores, also are first detected in the Late Devonian (Fammenian) (Gillespie et al., 1981). Without integuments, however, a primitive ovular megasporangium cannot be distinguished from a free-sporing megasporangium, so it is possible that non-integumented ovules evolved earlier. The difficulty in recognizing megaspores and megasporangia derived from ovules is illustrated by the initial description of Archaeosperma arnoldii megasporangia and megaspores. Until specimens with integuments were discovered, this structure could not be identified unambiguously as an ovular megasporangium/megaspore complex (Pettitt and Beck, 1968). Taken together, these observations demonstrate that any treatment of the origin of heterospory or the seed habit has a large hypothetical component linking disconnected data from modern and fossil lower vascular and seed plants and a generalized pattern of phylogenetic relationships among plants, with a framework of theoretical arguments.

\section{Progenetic Origin of Heterospory}

The heterosporous life history is characterized by gametophytes that are strictly unisexual and thus incapable of self fertilization. In almost all cases heterospory co-occurs with endospory, the sexual maturation of gametophytes while housed within the spore wall. Because they have no exosporic existence, endosporic gametophytes fix little carbon and do not acquire nutrients for continued growth. For heterosporous vascular plants available evidence suggests that the sex of each gametophyte is determined by the metabolic microenvironment encountered by each developing spore, not by sex chromosomes (Sussex, 1966; Bell, 1979). Any attempt to explain the evolution of heterospory should, then, address the evolution of endosporic development as well. Heterospory and endospory may be adaptively linked, but under independent developmental control.

\section{Gametophytic Progenesis-Origin of Endospory}

Paedomorphosis is the retention of ancestral juvenile characters by later ontogenetic stages of descendants (Gould, 1977). In the strongly biphasic vascular plant life history, paedomorphosis can be gauged relative to two developmental markers: meiosis, or perhaps the timing of sporangial initiation, in the sporophytic phase, and gametangial development in the gametophytic phase. Because the sporophyte and gametophyte are separate freeliving organisms at maturity in homosporous lower vascular plants, paedomorphosis can be expressed in either phase independently of the other. However, a change in the timing of either meiosis or gametangial initiation will have profound ecological and morphological consequences for the entire life history.

We suggest that the morphological transformation from homosporous plants with free- 


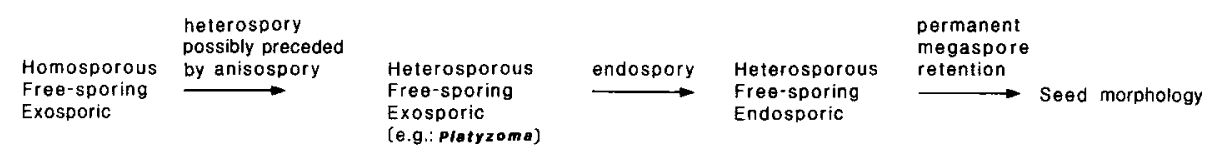

A

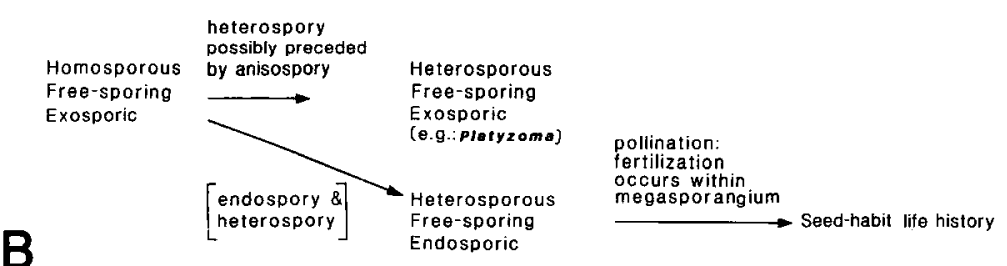

Fig. 1. Alternative views of character state distributions in the evolution of heterospory and the seed habit. A. "Traditional" view, in which all major variations on vascular plant life history are projected as steps in trend toward increasing enlargement and protection of the female gametophyte. Exosporic heterospory is a phase between homospory and endosporic heterospory largely due to the belief that evolution is a gradual, directional process; that a morphology can be included as a "step" means that it must be included. B. Scenario developed in this paper, in which heterospory is developmentally linked to endospory via progenesis. Exosporic heterospory and endosporic heterospory evolve independently. The critical phase of the life history we call the seed habit is fertilization occurring while the megaspore(s) is/are within the megasporangium, rather than permanent megaspore retention.

living bisexual gametophytes to heterosporous plants with endosporic unisexual gametophytes may have proceeded rapidly. By the precocious onset of sexuality, gametophytes could reach sexual maturity while still in the early endosporic phases of development. Such a transformation would likely be progenetic (Gould, 1977), because one of the major advantages of heterospory is the rapid completion of the sexual phases of the life cycle. The evolution of fully endosporic gametophytes need not have involved intermediate morphological stages.

\section{Origin of Separate Sexes}

The origin of strictly unisexual gametophytes, each of predetermined sex, is related adaptively to endosporic development. Unisexuality may, however, be a coincident epigenetic consequence of endospory, not its antecedent (Fig. 1B). This contrasts with the view that a free-sporing, exosporic, heterosporous life history (as in Platyzoma) is an intermediate evolutionary step between homospory and free-sporing, endosporic, heterospory (Fig. 1A).

Gametophytic unisexuality appears to be a position effect of the metabolic microenvironment of developing spores (Fig. 2). Endospory, once present, places developing gametophytes within the heterogeneous metabolic sphere of the sporophytic parent. Sporophytic control of gametophytic sex expression prevents the gametophyte from responding to environmental cues, as can free-living exosporic gametophytes (Voeller, 1971; Näf, 1979). Endosporic gametophytes in the most favorable metabolic microenvironments mature as females, while those in poorer metabolic microenvironments mature as males.

Position effects can be observed in bisporangiate strobili of many free-sporing heterosporous plants. In most living and fossil examples the megasporangia are located basally, where they are proximate to the nutrient source in the parent sporophyte, whereas microsporangia are located distally. Also indicative of the importance of position effects are observations by Bell (1979) that in some species of plants, both heterosporous and homosporous, female gametophytes are capable of apomixis while males are not. This suggests that the physiological state of females, which usually are larger and grow faster than males, permits the expression of sporophytic genes even in the absence of syngamy. The metabolic 


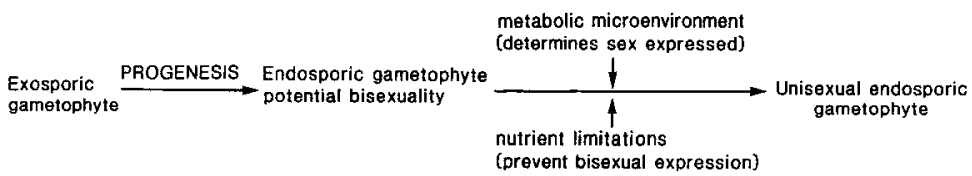

Fig. 2. Hypothetical transformation series from free-sporing homosporous plant with bisexual exosporic gametophyte to heterosporous plant with unisexual endosporic gametophyte. A combination of factors, resulting from paedomorphosis, control the ultimate expression in heterospory.

microenvironment of females at certain stages of their development influences the genes expressed.

Bell (1979) also discussed the importance of metabolic microenvironment in plant development and sexual expression. In some species of homosporous ferns, gametophytes developing from larger isospores tend to grow faster and to produce archegonia; smaller spores give rise to more slowly growing gametophytes that either produce antheridia or are induced to do so by antheridiogens produced by neighboring females (Voeller, 1971; Bell, 1979; Näf, 1979). This flexibility in sexual expression, which may include the potential for one gametophyte to produce gametes of both sexes, allocates the timing of gamete production and the determination of sex ratio in a gametophyte population to the gametophyte generation.

\section{Discussion: Heterospory}

It has long been recognized that homospory, the ancestral condition in vascular plants, has certain ecological and hence evolutionary limitations. The range of environments open to a homosporous plant species is limited by the reproductive requirements of the gametophyte, including the need for moist conditions for syngamy to occur. This places limits on the conditions under which the sexual life cycle can be completed. Should sporophytes arise that are tolerant of very dry, physically stressful conditions, gametophytes developing from their meiospores might not be able to reproduce sexually, hence compromising the fitness of the dry-tolerant sporophytes. There is, then, a functional dichotomy in homosporous plants between the sporophyte as the agent of dispersal (via spores), and the gametophyte as the point of syngamy. The requirements of the gametophyte place an ecological and hence evolutionary constraint on this type of life history.

Free-sporing heterosporous plants are far more limited ecologically by the peculiarities of their life history than are homosporous species. In the limited spectrum of environments that free-sporing heterosporous plants exploit, however, their life history appears to have functional advantages over homospory. In these plants the obligately unisexual male and female gametophytes are functionally analogous to sperm and egg. They are released directly into the environment shortly after meiosis. There is, then, a near simultaneity of spore, gametophyte, and gamete production. One of the key attributes of the extreme compression of the gametophytic phase of the life cycle thus is apparent: gametophytes no longer directly control the sex ratio, as they do in homosporous plants. A critical role of the gametophyte in the plant's life history has been transferred to the sporophyte. The necessity of environmental moisture for sexual reproduction still is present. Consequently, one might expect in dry habitats to find apomictic sporophyte production, which avoids the swimming sperm stage.

The heterosporous sexual system is most advantageous in aquatic and semi-aquatic habitats because these exhibit physical conditions more consistently favorable for the release of sperm and egg. In fact, in such environments heterosporous species may have a distinct advantage over homosporous forms, because they release gametophytes well suited functionally to aquatic conditions. In heterosporous plants the sporophyte dictates when, where, 
and under what physical conditions gametophytes will perform their functions. The sporophyte is not the optimal stage in the free-sporing life cycle in which to determine sex ratio and the timing of syngamy. Due to lags between the reading of environmental cues and the time of release of functional sperm and egg (strictly unisexual male and female gametophytes), the potential for the gametophytes to encounter unfavorably dry environments in which syngamy cannot occur is high. This problem will be most severe in environments with dry or only ephemerally moist surfaces (most terrestrial habitats).

Some heterosporous pteridophytes do occur in terrestrial habitats, but these plants rely to a great extent on asexual reproduction. Apogamy or parthenogenesis has been reported in fully or mostly terrestrial species of Selaginella (Lyon, 1901, 1904; Bruchmann, 1912, 1920; Hieronymus, 1913; Geiger, 1935; Steil, 1939, 1951; Horner and Arnott, 1963; Webster and Steeves, 1974), Marsilea (Shaw, 1897; Strasburger, 1907; Gupta, 1962; Bhardwaja and Abdullah, 1971), Isoetes (Pant and Srivastava, 1965), and Regnellidium (Mahlberg and Baldwin, 1975). We did not locate reports of apomixis in Pilularia, Azolla, or Salvinia, the latter two floating aquatics; this is consistent with the prediction that apomixis will be of greatest importance in non-aquatic environments, where sexual reproduction frequently will be hampered by environmental extremes. Heterospory and apomixis co-occur frequently in fully terrestrial habitats, and only rarely in aquatic or semi-aquatic settings. Reduced sexual reproduction in terrestrial populations of these plants may lead to lowered levels of genetic variation within populations, hence reducing the ability of populations to survive environmental fluctuations. Populations may be unable to adjust to periodic or continuous change in the local environment, whether biotic or abiotic in nature (Van Valen, 1973).

The form that is frequently proposed as an evolutionary intermediate between homospory and free-sporing heterospory with endosporic gametophytes is heterospory with exosporic unisexual gametophytes (cf. Tiffney, 1981). Although it makes an acceptable morphological intermediate, we believe it is an unlikely evolutionary intermediate because of ecological constraints to its success. This form combines the ecological limitations of both homospory and heterospory with none of the advantages of either. In homospory, free-living gametophytes essentially control sex ratio and the timing of syngamy, and are potentially bisexual. Thus, they have mechanisms to control reproduction, their basic function, and, due to the independent nature of the gametophyte phase, made possible by potential bisexuality, they are excellent dispersers to and colonizers of a variety of habitats. Freesporing heterospory with endosporic gametophytes has advantages over life histories with exosporic gametophytes in environments that require rapid completion of sexual phases of the life cycle. It also confers an advantage when disruptive selection on independently living sporophyte and gametophyte phases reduces overall fitness, because, with condensation of the sexual phase, day to day selection is focused on the sporophyte alone. The general confinement of sexually reproducing free-sporing heterosporous plants to persistently moist conditions is, however, a consequence of the functional constraints of this system.

The living ferm Platyzoma (Tryon, 1964) usually is offered as an example of a form intermediate between homospory and free-sporing heterospory. This heterosporous fern has free-living but strictly unisexual gametophytes. Consequently, gametophytes cannot control the sex ratio, and they lack the colonizing capabilities that accompany potentially bisexual gametophytes. Furthermore, the life cycle is not compressed as in heterosporous species with endosporic gametophytes. Like homosporous species, however, Platyzoma requires predictably moist conditions for successful syngamy, and places strong gametophytic functional constraints on sporophyte evolution. The ecological constraints inherent in this life history make it an unlikely candidate for evolutionary intermediacy. Its inclusion as a state that must be passed through on the way to more derived kinds of morphology reflects a philosophy of incorporating all known morphologies into "trends," reducing the 
size of morphological "gaps," and thus bringing any scenario more in line with the expectations of gradual, adaptive evolutionary models.

Heterochrony provides a means to account for the independent evolution of heterospory in most lineages of lower vascular plants (i.e., Lepidodendrales, Selaginellales, Calamitales, Salviniales, Marsileales, Progymnospermopsida), without the need for a hypothetical Platyzoma-like stage in each lineage. Thus, although our scenario (Fig. 1B) is superficially less parsimonious than the "traditional" view (Fig. 1A), the independent evolution of heterospory in association with endospory in several plant lineages makes such a developmental explanation seem at least as likely. This clarifies the architectural convergences and the convergent habitat preferences of heterosporous plants as consequences of certain lifehistory and developmental modifications. In this sense function and architecture, although closely related, can be considered as separate problems and brought into sharper focus.

\section{Seed Habit: Origin}

The seed habit life history (as opposed to seed morphology) differs from free-sporing heterospory in just one fundamental way, by the delivery of the male gametophyte directly to the female gametophyte, i.e., pollination. This bypasses the free release of the female into the environment, and thus the environmental limitations placed on the free-sporing system by water-mediated fertilization. Pollination by its nature places plants with this life history in an entirely different ecological, and hence selective, context than lower vascular plants. It constitutes a fundamental phenotypic breakthrough that opens to these plants a vast resource pool, the terrestrial landscape, previously unexploited or poorly exploited by sexually reproducing plants.

The transformation from free-sporing heterosporous plants to seed plants conventionally calls for reduction in megaspore number per sporangium, permanent megaspore retention within the sporangium, and megasporangial integumentation (Smith, 1964). However, none of these structural features is essential to the functional nature of the seed habit. In terms of life history, pollination is the sole element of significance (Fig. 1B). The earliest plants with the ecological capabilities of seed plants may have had unintegumented megasporangia and multiple megaspores per sporangium, and may have released megaspores from the sporangium once fertilization occurred. This morphological configuration would not be distinguishable in structure from free-sporing heterospory, yet its ecological and evolutionary potentials would be quite different. Once this evolutionary transition had been made, plants exhibiting a "pollination syndrome" would find themselves in a fundamentally different selective environment in which morphological change might be constrained only by the requirement to persist and reproduce. We do not imply that the earliest forms with a seed-plant life history must have had multiple megaspores per sporangium. While such forms might not be included in a morphological definition of the seed, they do exhibit the essential characteristics of the seed-plant life history.

In this light, it is as likely that seed plants were derived directly from homosporous ancestors, via progenesis, as from heterosporous "intermediates." A direct homosporous ancestry for the seed plants was suggested by Thomson (1927) many years ago. Morphological arguments against Thomson's analysis (e.g., Pettitt, 1970) are founded on assumptions of gradual transformation of form. In fact, known reproductive structures from the fossil record do not resolve this question. A phylogenetic analysis based on vegetative organs, or on a suite of vegetative and reproductive organs (determined from reconstructing whole plants) may provide a more complete picture. There are indications that seed plants are polyphyletic, a subject of considerable current debate (Chaloner et al., 1977; Beck, 1981; Stewart, 1981; Rothwell, 1982; Meyen, 1984; Crane, 1985; Doyle and Donoghue, 1986). 


\section{Seed Plants: Diversification}

In considering the diversification of seed plants it is important to separate the pattern revealed by the fossil record from the interpretation of that pattern based on preconceived models of evolution. The early fossil record of seed plants is largely one of isolated ovules, meaning specifically: integumented megasporangia with single functional megaspores. Therefore, our understanding of the evolution of the seed-plant life history focuses heavily on the evolution of ovular morphology. The relationship between the evolution of ovular morphology and vegetative morphology is conjectural due to the lack of "whole-plant" assemblages of organs from the critical part of the fossil record. However, variation in ovular morphology and the pattern of ovular diversity through time do provide conservative, reasonable gauges of the evolutionary dynamics of early seed plants.

The fossil record reveals that when ovules first appear in the Late Devonian few architectures are represented (Gillespie et al., 1981; Scheckler, 1985). In the Lower Carboniferous the number of ovular architectures increases enormously. Subsequently, there is a decline in architectural types, with only one or two major forms occurring in the Upper Carboniferous. This pattern of diversity is similar in basic form to those detected by Sepkoski $(1978,1979,1981)$ for Paleozoic marine invertebrates, and by Niklas et al. $(1980,1983)$ for terrestrial plants. However, concomitant with this pattern of change in ovular architecture, the diversity of seed-plant species rises more or less continuously during the same time period (Niklas et al., 1980, 1983).

The earliest ovules are early Late Devonian in age (Gillespie et al., 1981), and conform in basic morphology to Archaeosperma, described from slightly younger rocks by Pettitt and Beck (1968). This form, with radiospermic symmetry, mostly unfused, converging integumentary lobes, and an enclosing cupule, is the predominant ovular type of the Late Devonian. In the latest Late Devonian the first traces of architectural diversification appear as new radiospermic (Matten et al., 1980a, 1980b) and platyspermic (Chaloner et al., 1977) forms are found. It is in the Lower Carboniferous that the great diversification of ovular architectures occurs. Over 12 structurally distinct genera have been described, mostly through the work of Long (see 1975 summary), representing a multi-dimensional array of integumentary form (number, degree of fusion, and shape of integument lobes) and ovular shape. This spectrum of forms is much greater than has existed since. It is important to note that these forms are coexistent; they do not form a morphological-stratigraphic progression from those deemed more "primitive" to those deemed more "advanced," relative to modern ovules (Steeves, 1983). The stratigraphic imprecision in this record is minimal compared to the overall pattern. By the Upper Carboniferous (probably late Lower Carboniferous) this architectural diversity had declined. Ovules with complete integuments and apical micropyles, possibly a polyphyletic morphology, are overwhelmingly predominant. This is the ovular form that persists today. Despite this decline in the variety of architectures, the number of ovule species increased greatly in the Upper Carboniferous, as variations on the closed-integument architecture.

Morphological modernization of the ovule generally is treated in a strictly structural context, superimposing the expectation of continuous, progressive, gradual evolution on the ovular morphologies revealed by the fossil record. In keeping with these expectations, fossil ovules have been arranged in a morphological series (Fig. 3) from forms with nearly free integumentary lobes to those with completely fused integuments (Andrews, 1963; Smith, 1964; Long, 1966). However, this directional pattern is not completely consistent with the available data. First, the hypothetical morphological progression does not conform to the stratigraphic distribution of these ovules. Indeed, the largest number of the ovules coexisted, and thus, presumably, were more or less equally "fit" during the early radiation, a pattern more congruent with an environment of low rather than intense directional selection. Second, many of the known forms differ greatly from those that make up the 


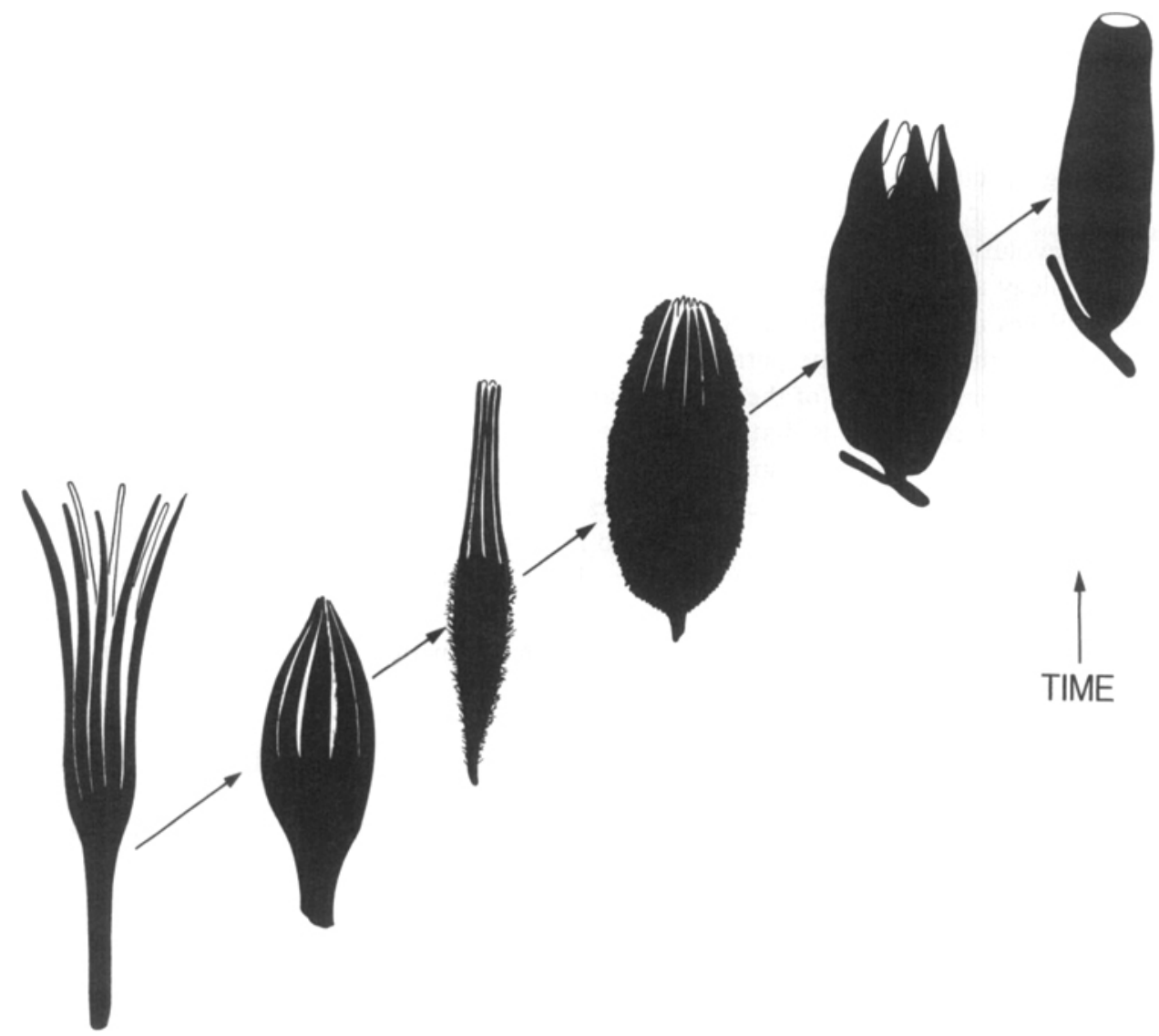

Fig. 3. Hypothetical transformation series from ovules with free integumentary lobes to ovules with closed integuments and apical micropyle. Modified from Andrews (1963). Sequence represents this transformation occurring as a gradual, adaptive trend.

"main trend," and can be included in it only with difficulty; this indicates that the pattern was not a simple linear progression. Although there may be some linear relationships among the known ovular morphologies of the time, these can be assessed only by a phylogenetic analysis of the whole plants, independent of any particular evolutionary paradigm.

The timing of appearance and the distribution of early ovules suggests nonlinear diversification (Fig. 4). This may reflect the ecological fabric of the Late Devonian/Lower Carboniferous selective landscape. Initial stages of the diversification do not appear to have been directed strongly by natural selection. Rather, this is a pattern of diversification into a physical-biotic environment with areas of little or no interspecific competition for resources, or at least little selective difference that may relate to integumentary design. Early ovular evolution thus reflects what Arthur (1984) has labeled n-selection. As we envision it, any ovular morphology could survive, as long as it did not depress reproduction too severely or obviate it entirely. In a very "open" selective landscape, isolated populations capable of exploiting particular local subenvironments could establish founder lineages and rapidly evolve divergent ovular forms. There were large areas of reduced or no biotic competition in which survival of these lineages was controlled primarily by abiotic selection focused largely on vegetative traits. Selection was principally a filter (Rothwell, 1987), at least at the stage of establishment of species stem-populations.

The termination of this diversification of major ovular architectures, and the subsequent reduction in the spectrum of integumentary variation to one basic architectural plan, 


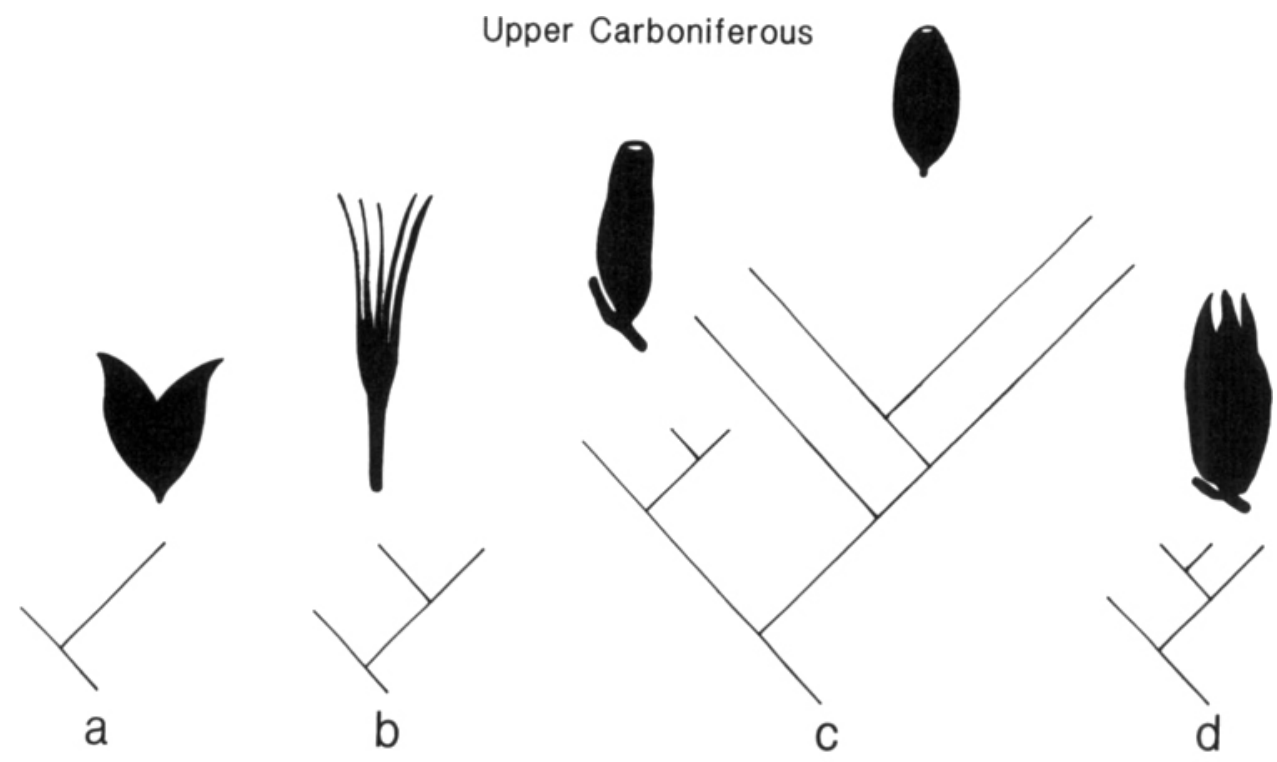

\section{Lower Carboniferous \\ Late Devonian}

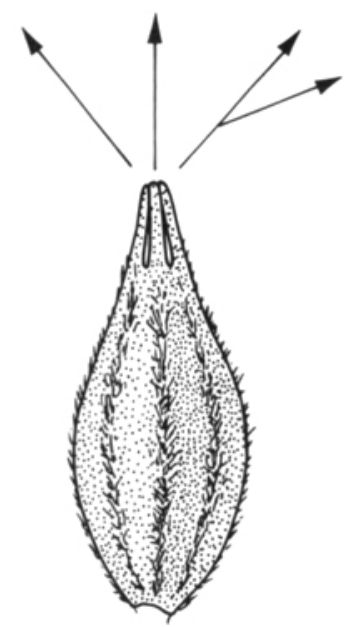

Fig. 4. Hypothetical pattern of diversification of early seeds, based on the stratigraphic pattern of distribution of ovules. Earliest ovule is illustrated as Archaeosperma arnoldii, redrawn from Pettitt and Beck (1968). The derived forms, represented as a-d, would have a spectrum of integumentary morphologies similar to that shown in Fig. 3. Ultimately one form of ovule, that with an unlobed integument, prevails, as ecological interactions among seed plants increase.

appears to be an extension of this same ecological scheme, falling within the predictions of Sepkoski's (1979) Kinetic Theory. As the areas occupied by seed plants increased, interactions among independent lineages became more common (Fig. 4). This resulted in an ever-increasing level of biotic competitive interactions. Morphologies that most limited 
the evolution of further life-history refinements were eliminated, and the likelihood of survival of highly divergent morphologies declined greatly. The ultimate success of species with closed integuments reflects the broad degree of modification this form can support. It is a substrate for evolution of seed dormancy, dispersal by animals and other agents, and protection against predation. Thus, although ovular form may have had little significance in the early radiation of seed plants, its relationship to potential life-history complexity played a much greater role as competitive interactions increased. Although total species diversity continued to increase (Niklas et al., 1980; Knoll et al., 1984), new morphologies evolving during the later phases of this process were minor modifications on existing forms, particularly those with complete or nearly complete integuments.

\section{Acknowledgments}

For comments on earlier drafts we thank James Eckenwalder and Kevin Nixon. Reviewers provided constructive comments. Figures were prepared by Mary Parrish.

\section{Literature Cited}

Andrews, H. N. 1963. Early seed plants. Science 142: 925-931.

- P. G. Gensel and W. H. Forbes. 1974. An apparently heterosporous plant from the Middle Devonian of New Brunswick. Palaeontology 17: 387-408.

Arthur, W. 1984. Mechanisms of morphological evolution. John Wiley, New York.

Beck, C. B. 1981. Archaeopteris and its role in vascular plant evolution. Pp. 193-230. In: K. J. Niklas (ed.), Paleobotany, paleoecology and evolution, vol. 1. Praeger, New York.

Bell, P. R. 1979. The contribution of the ferns to an understanding of the life cycles of the vascular plants. Pp. 58-85. In: A. F. Dyer (ed.), The experimental biology of ferns. Academic Press, New York.

Bhardwaja, T. N. and S. Abdullah. 1971. Some observations on parthenogenetic sporelings of the water fern Marsilea. Nova Hedwigia 21: 521-528.

Bruchmann, H. 1912. Zur Embryologie der Selaginellaceen. Flora 104: 180-224.

- 1920. Von der Selaginella helvetica im Vergleiche mit den anderen europäischen SelaginellaArten. Flora 113: 168-177.

Chaloner, W. G. 1967. Spores and land-plant evolution. Rev. Palaeobot. Palynol. 1: 83-93.

- A. J. Hill and W. S. Lacey. 1977. First Devonian platyspermic seed and its implications in gymnosperm evolution. Nature 265: 233-235.

Crane, P. R. 1985. Phylogenetic analysis of seed plants and the origin of angiosperms. Ann. Missouri Bot. Gard. 72: 716-793.

Doyle, J. A. and M. J. Donoghue. 1986. Seed plant phylogeny and the origin of the angiosperms: An experimental cladistic approach. Bot. Rev. (Lancaster) 52: 321-431.

Geiger, H. 1935. Untersuchungen an Selaginella (Makroprothallien, Befruchtung und Apomixis). Flora 129: 140-157.

Gillespie, W. H., G. W. Rothwell and S. E. Scheckler. 1981. The earliest seeds. Nature 293: 462464.

Gould, S. J. 1977. Ontogeny and phylogeny. Belknap Press, Cambridge, Massachusetts.

Gupta, K. M. 1962. Marsilea. Council of scientific and industrial research. Botanical Monograph (New Delhi) 2.

Hieronymus, G. 1913. Neue Selaginella-Arten Papusiens. Bot. Jahrb. Syst. 50: 1-45.

Horner, H. T. and H. J. Arnott. 1963. Sporangial attachment in North American species of Selaginella. Bot. Gaz. (Crawfordsville) 124: 371-383.

Knoll, A. H., K. J. Niklas, P. G. Gensel and B. H. Tiffney. 1984. Character diversification and patterns of evolution in early vascular plants. Paleobiology 10:34-47.

Long, A. G. 1966. Some Lower Carboniferous fructifications from Berwickshire, together with a theoretical account of the evolution of ovules, cupules and carpels. Trans. Roy. Soc. Edinburgh 66: 345-375.

- 1975. Further observations on some Lower Carboniferous seeds and cupules. Trans. Roy. Soc. Edinburgh 69: 267-293.

Lyon, F. M. 1901. A study of the sporangia and gametophytes of Selaginella apus and Selaginella rupestris. Bot. Gaz. (Crawfordsville) 32: 124-141, 170-194.

1904. Evolution of the sex organs of plants. Bot. Gaz. (Crawfordsville) 37: 281-293. 
Mahlberg, P. G. and M. Baldwin. 1975. Epidermal studies on megaspore viability, parthenogenesis and sporophyte formation in Marsilea, Pilularia and Regnellidium. Bot. Gaz. (Crawfordsville) 136: 269-273.

Matten, L. C., W. S. Lacey and R. C. Lucas. 1980a. Studies on the cupulate seed genus Hydrasperma Long from Berwickshire and East Lothian in Scotland and County Kerry in Ireland. J. Linn. Soc., Bot. 81: 249-273.

- - B. I. May and R. C. Lucas. 1980b. A megafossil flora from the uppermost Devonian near Ballyheigue, Co. Kerry, Ireland. Rev. Palaeobot. Palynol. 29: 241-251.

Meyen, S. V. 1984. Basic features of gymnosperm systematics and phylogeny as evidenced by the fossil record. Bot. Rev. (Lancaster) 50: 1-111.

Näf, U. 1979. Antheridiogens and antheridial development. Pp. 435-470. In: A. F. Dyer (ed.), The experimental biology of ferns. Academic Press, New York.

Niklas, K. J., B. H. Tiffney and A. H. Knoll. 1980. Apparent changes in the diversity of fossil plants. A preliminary assessment. Evol. Biol. 12: 1-89.

$\longrightarrow,-$ and $\longrightarrow$ 1983. Patterns in vascular land plant diversification. Nature 303: 614 616.

Pant, D. D. and G. K. Srivastava. 1965. Cytology and reproduction of some Indian species of Isoetes. Cytologia 30: 239-251.

Pettitt, J. M. 1970. Heterospory and the origin of the seed habit. Biol. Rev. Cambridge Philos. Soc. 45: $401-415$.

and C. B. Beck. 1968. Archaeosperma arnoldii-A cupulate seed from the Upper Devonian of North America. Contr. Mus. Paleontol. Univ. Michigan 22: 139-154.

Rothwell, G. W. 1982. New interpretations of the earliest conifers. Rev. Palaeobot. Palynol. 37: 728.

1987. The role of development in plant phylogeny: A paleobotanical perspective. Rev. Palaeobot. Palynol. 50: 97-114.

Scheckler, S. E. 1985. Seed plant diversity in the Late Devonian (Fammenian) [Abstract]. Amer. J. Bot. 72: 900 .

Sepkoski, J. J., Jr. 1978. A kinetic model of Phanerozoic taxonomic diversity. I. Analysis of marine orders. Paleobiology 4: 223-251.

. 1979. A kinetic model of Phanerozoic taxonomic diversity. II. Early Phanerozoic families and multiple equilibria. Paleobiology 5: 222-251.

- 1981. A factor analytic description of the Phanerozoic marine fossil record. Paleobiology 7 : $36-53$.

Shaw, W. 1897. Parthenogenesis in Marsilea. Bot. Gaz. (Crawfordsville) 24: 114-117.

Smith, D. L. 1964. The evolution of the ovule. Biol. Rev. Cambridge Philos. Soc. 39: 137-159.

Steeves, T. A. 1983. The evolution and biological significance of seeds. Canad. J. Bot. 61: 35503560 .

Steil, W. N. 1939. Apogamy, apospory and parthenogenesis in the pteridophytes. Bot. Rev. (Lancaster) 5: $433-453$.

- 1951. Apogamy, apospory and parthenogenesis in the pteridophytes. II. Bot. Rev. (Lancaster) 17: 90-104.

Stewart, W. N. 1981. The Progymnospermopsida: The construction of a concept. Canad. J. Bot. 59: 1539-1542.

Strasburger, E. 1907. Apogamie bei Marsilia. Flora 97: 123-191.

Sussex, I. M. 1966. The origin and development of heterospory in vascular plants. Pp. 141-152. In: E. G. Cutter (ed.), Trends in plant morphogenesis. Longmans, London.

Thomson, R. B. 1927. Evolution of the seed habit in plants. Proc. \& Trans. Roy. Soc. Canada, ser. 3: 21, part 1, Section V (Biology): 228-272.

Tiffney, B. H. 1981. Diversity and major events in the evolution of land plants. Pp. 193-230. In: K. J. Niklas (ed.), Paleobotany, paleoecology and evolution, vol. 2. Praeger, New York.

Tryon, A. F. 1964. Platyzoma-A Queensland fern with incipient heterospory. Amer. J. Bot. 51: 939-942.

Van Valen, L. 1973. A new evolutionary law. Evol. Theory 1: 1-30.

Voeller, B. 1971. Developmental physiology of fern gametophytes: Relevance for biology. BioScience 21: $266-275$

Webster, T. R. and T. A. Steeves. 1974. Reproductive biology in a xerophytic Selaginella [Abstract]. Amer. J. Bot. 61: 39. 